\title{
Construcción de la historia reciente del ferrocarril de La Araucanía (Chile) desde la percepción de sus trabajadores ${ }^{1}$
}

\author{
Building the recent history of the railway of \\ La Araucanía (Chile) from its workers point of view \\ Hernán Riquelme Brevis ${ }^{\mathrm{a}}$ \& Fernando Oyarce Ortuya ${ }^{\mathrm{b}}$ \\ aUniversidad Arturo Prat, Chile, $\measuredangle$ h.riquelmebrevis@gmail.com \\ [orcid.org/0000-0002-9686-6284] \\ bUniversidad Autónoma de Chile, Chile, fernando.oyarce@iehabitat.cl \\ [https://orcid.org/0000-0002-4936-1128]
}

\section{RESUMEN}

El presente artículo tiene por objetivo analizar la percepción de los trabajadores ferroviarios de La Araucanía, Chile, en relación con el papel desempeñado por el ferrocarril en las dinámicas socioculturales y económicas de la región. A partir de una metodología cualitativa, donde se entrevistó a veintitrés trabajadores y extrabajadores ferroviarios, se desarrolló el trabajo de campo en ciudades históricas de la región como Victoria, Lautaro, Temuco y Renaico, las cuales se gestaron territorialmente en estrecha relación con la inserción del ferrocarril desde la segunda mitad del siglo XIX. Dentro de los hallazgos cabe destacar la relevancia del ferrocarril en la vida cotidiana de los habitantes de la región, el rol del ferrocarril en la participación social de los ciudadanos, la trascendencia del patrimonio ferroviario desde el encuentro entre lo material y lo subjetivo y las transformaciones en las formas de interacción social de los trabajadores ferroviarios.

PALABRAS CLAVE: patrimonio ferroviario, vida cotidiana, trabajadores ferroviarios, memoria, sur de Chile.

1 Este artículo fue desarrollado mediante los proyectos VRIIP0177-16, financiado por la Vicerrectoría de Investigación, Innovación y Postgrado de la Universidad Arturo Prat y DIUA 170-2019, financiado por la Vicerrectoría de Investigación y Postgrado de la Universidad Autónoma de Chile. Los autores, como parte del claustro académico del Magíster en Gestión del Patrimonio y Turismo Sostenible (Universidad Autónoma de Chile), agradecen los comentarios de los revisores anónimos. 


\section{ABSTRACT}

The present article aims to analyze the perception of the railway workers from La Araucanía, Chile, regarding the role played by the railway in sociocultural and economic dynamics of the Region. The fieldwork was carried out in the Region's historical cities, such as Victoria, Lautaro, Temuco and Renaico, which were developed -in terms of territory- very closely-related to the incorporation of the railway during the second half of the XIX century. The research used a qualitative methodology, in which twenty-three railway workers and former workers were interviewed. Among the findings, it is worth mentioning: the importance of the railway in the daily lives of the Region's inhabitants, the role of the railway in the social participation of citizens, the significance of the railway patrimony from the encounter between the material and the subjective, and the transformations in the social interaction ways of the railway workers.

KEY WORDS: railway patrimony, daily life, railway workers, memory, south of Chile.

\section{INTRODUCCIÓN}

La historia de La Araucanía ha estado fuertemente influenciada por el papel del ferrocarril en las dinámicas territoriales, la construcción del paisaje cultural y las prácticas de movilidad desarrolladas por sus habitantes. Con el objetivo de organizar y evidenciar las vicisitudes socioeconómicas e históricas que ha experimentado el ferrocarril en la historia de Chile a través de la literatura relativa a la temática, se identifican tres momentos clave que permiten comprender y estructurar la tradición ferroviaria de La Araucanía, logrando develar las luces y sombras de la región desde su desarrollo territorial. Estos momentos están relacionados íntimamente con los procesos de inserción, consolidación, fragmentación y revitalización del ferrocarril a nivel nacional (Marín, 1901; Alliende, 1993; Guajardo, 2007).

El primer periodo comprende fines del siglo XIX y comienzos del siglo XX. Este momento responde a la expansión ferroviaria en el sur del país cuya génesis recae en fines políticos asociados a la conectividad, vigilancia y soberanía de un territorio fronterizo y considerado como indómito por los foráneos. En este sentido, las transformaciones tecnológicas, amparadas en la inserción de la maquinaria ferroviaria, quedan ampliamente documentadas por el ingeniero belga Gustave Verniory, quien trabajó en la construcción de la línea férrea, identificando aspectos culturales y territoriales propios de la región. Para Verniory (2005), la inserción del ferrocarril, junto con entregar conectividad, significó el encuentro de diversas culturas que convivieron en un espacio social heterogéneo, conformado por chilenos, colonos y mapuche que cohabitaban en ciudades como Lautaro, Victoria y Temuco, las cuales por ese entonces estaban en plena gestación, desarrollo y planificación. 
El segundo periodo comprende la segunda parte del siglo XX. En esta fase se distingue la emergencia del ferrocarril como un objeto interurbano consolidado tanto en diversos ámbitos de la vida cotidiana como en la planificación de las ciudades. Junto con ser un dispositivo de transporte de primera necesidad para los habitantes de la región también juega un papel crucial en la socialización ya que incentiva y promueve vínculos afectivos, arraigo e identidad con el territorio. La investigación de Obreque (2001) permite conocer las dinámicas socioculturales particulares de la región que se gestaban en función del ferrocarril. Trabajo, comercio y turismo emergen como pilares fundamentales en la vida social, entrelazando el transporte con la consolidación de rutinas, lugares y rutas que se fortalecen a medida que el ferrocarril interconecta la región y el país. Asimismo, a fines de este periodo (décadas de los ochenta y noventa) se deja entrever el ocaso del transporte ferroviario con la consolidación de otros medios de transporte interurbano, cuestión que impactó en la reducción del servicio, afectando no solo las posibilidades de movilidad de la población, sino también costumbres, tradiciones y actividades desarrolladas por las personas en concordancia directa con este dispositivo de transporte. En este periodo queda en evidencia el desligue paulatino del Estado en la actividad ferroviaria, consolidándose la privatización del servicio (Riquelme, 2017a).

El tercer periodo sintetiza comienzos del siglo XXI hasta los días actuales. Se observa un servicio ferroviario de transporte de pasajeros deprimido, el cual cubre la ruta VictoriaTemuco, interconectando Lautaro y Perquenco, así como las localidades de Quillén, P.U.A. y Pillanlelbún. Este servicio funciona en un rango de 65 kilómetros enlazando las provincias de Malleco y Cautín en una hora y treinta minutos de viaje. En la región no existen rutas en otras comunas más allá de las nombradas que cuenten con servicios operativos, dejando en comunas por donde antaño circulaba el transporte de pasajeros ruinas y estaciones que solo son utilizadas por los trenes de carga.

Cada uno de los momentos, relativos y diferenciados en cuanto a la duración, engloba los avances y retrocesos económicos, sociales y culturales de La Araucanía, plasmando diversas costumbres y tradiciones que en algunas ocasiones perduran en la actualidad. El ferrocarril se presenta como un objeto interurbano que arrastra consigo un cúmulo de experiencias y acciones preservadas por la memoria histórica de una región desplazada del progreso económico y el reconocimiento intercultural.

Con el objetivo de conocer la percepción de los trabajadores ferroviarios respecto a las transformaciones económicas y culturales de la región en relación con el papel del ferrocarril y su connotación patrimonial, para los efectos de esta investigación se enfatizará en el tercer periodo, aportando en la elaboración de una radiografía actual de la región desde el relato de los protagonistas de la historia contemporánea del ferrocarril. Se reconoce que la emergencia de uno de estos periodos no significa la desaparición y superación del que precede o antecede, por ende, existe una relación dialéctica entre los diversos momentos históricos que componen la historia del ferrocarril en La Araucanía. 
El artículo integra cuatro secciones, además de la introducción. En la primera se desarrolla una discusión conceptual respecto al patrimonio y su connotación material e inmaterial. En la segunda sección se exhibe la metodología utilizada en el estudio, así como las respectivas técnicas de recolección de información. En la tercera sección se presentan los hallazgos de la investigación organizados en función de sus respectivas categorías. Finalmente, se comparte una discusión analítica con el objetivo de reflexionar respecto a la relevancia del patrimonio ferroviario en la historia del país, así como el rol que ocupa en los procesos económicos y culturales actuales de La Araucanía.

\section{DEVELANDO LA TRADICIÓN FERROVIARIA: PATRIMONIO, HISTORIA Y PAISAJES}

\section{Apuntes sobre la inserción del ferrocarril en La Araucanía}

La región de La Araucanía está conformada administrativamente por dos provincias creadas el año 1887. La provincia de Malleco, cuya capital es la ciudad de Angol, alberga once comunas, y, la provincia de Cautín, cuya capital es Temuco (capital regional), alberga las veintiún comunas restantes. La población actual de la región llega a 957.224 personas (Censo, 2017). Dentro de las características sociodemográficas, cabe destacar que la tasa de personas en situación de pobreza por ingresos a nivel nacional es liderada por La Araucanía, con una cifra que alcanza el 17,2\% (Casen, 2017).

En términos históricos, durante la segunda mitad del siglo XIX comienzan a efectuarse los trabajos ferroviarios que darán vida al funcionamiento del ferrocarril en el sur de Chile. A manera de contextualización, Alliende (2001) describe la intromisión del ferrocarril representando el escenario social de aquellos tiempos:

Cornelio Saavedra iniciaría la ocupación de La Frontera. En 1862, echa las bases de la ciudad de Angol, a poca distancia de la antigua ciudad, destruida dos siglos antes por los mapuches. En 1868 se reconstruye la ciudad de Cañete y se funda Collipulli. En 1873 se comienzan a vender públicamente grandes terrenos en la Frontera; se establecen haciendas bajo la protección de las guarniciones. En 1878 se fundan las ciudades de Los Sauces y Traiguén. Con el retiro de las tropas de línea de La Frontera debido a la Guerra del Pacífico, la situación de los habitantes en esta zona se hace precaria. En 1881, se fundan nuevos fuertes y el 1 de enero de 1883, la región comprendida entre el río Malleco al norte, y el río Toltén al sur, era incorporada a la República de Chile y formaba el "Territorio de Colonización”, cuyo gobernador residía en Angol. Las tribus indígenas fueron sometidas a reducciones para evitar nuevas sublevaciones y con ello el gobierno contó con dos millones de hectáreas de terreno extremadamente útiles, los que comenzó a repartir entre colonos extranjeros. Desde 1883, comenzaron a llegar desde el puerto de Talcahuano a la región de La 
Frontera colonos suizos, alemanes, belgas, franceses, rusos, ingleses, españoles e italianos, los que en 1890 sumaban 6.894. Desde 1843 a 1885 la población de Chile se había duplicado. En febrero de 1887, el Territorio de Colonización se convirtió en las provincias de Malleco y Cautín (p. 154).

La intromisión del ferrocarril está íntimamente ligada al espíritu de soberanía y ocupación de un territorio observado por las autoridades de la época como conflictivo y problemático producto de la organización mapuche. Las tácticas empleadas consistieron en la colonización y la comunicación del territorio con la zona norte y sur del país. Uno de los principales gestores de la construcción de los ramales en la región fue Gustave Verniory, ingeniero belga que vivió por largos años en la región construyendo la ruta del ferrocarril al unir ciudades como Collipulli, Victoria, Lautaro y Temuco.

El ferrocarril emerge como un dispositivo que permite conectar, vigilar, organizar y estructurar La Araucanía tanto en términos intrínsecos, desde la comunicación entre las principales ciudades de la región, como extrínsecos, con las regiones aledañas y la capital nacional. Según González y Bernedo (2013), tras la conquista de La Araucanía², el gobierno de turno puso en marcha un plan de obras públicas que incluyó la inserción del ferrocarril con el objetivo de dar garantías al Estado sobre el territorio conquistado.

Tras más de cien años de instalación en la región, el ferrocarril ha mutado considerablemente, dejando operativo un servicio de pasajeros que funciona en 65 kilómetros permitieron conectar Victoria, Lautaro, Perquenco y Temuco. De las grandes edificaciones y comercio aledaño, en muchas de las ciudades por donde antiguamente transitaba, quedan solo ruinas que permiten imaginar la interacción que se gestó tiempo atrás. No obstante, continúa siendo un medio de transporte reconocido y admirado por los ciudadanos con un dejo de nostalgia que, a través de proyectos de trenes turísticos ${ }^{3}$, recuerda las portentosas máquinas pasadas. En la Fig. 1 puede apreciarse la ubicación geográfica en la región de las cuatro principales ciudades de estudio y sus respectivas vías férreas.

\section{El ferrocarril: entre paisajes y patrimonio}

La historia de la sociedad occidental contemporánea se traza en directa relación con la inserción del ferrocarril durante el siglo XIX (Burman \& Stratton, 1997; Douet, 2012; Abhishek \& Taha, 2014). Recientes investigaciones han puesto en evidencia el papel del ferrocarril en el desarrollo cultural y económico, así como aspectos vinculados a la interpretación del viaje (Delgado et al. 2007; Maia \& Diaz, 2010; Ferrari, 2012; Yuln et al. 2017; Riquelme \& Lazo, 2019). Estas investigaciones conjugan factores materiales y subjetivos en la comprensión de

2 Proceso que se desarrolló a través de la violencia y el exterminio de una parte importante del pueblo mapuche (1861-1883).

3 Iniciativa de Grupo EFE a través del proyecto "Trenes turísticos de Chile". 


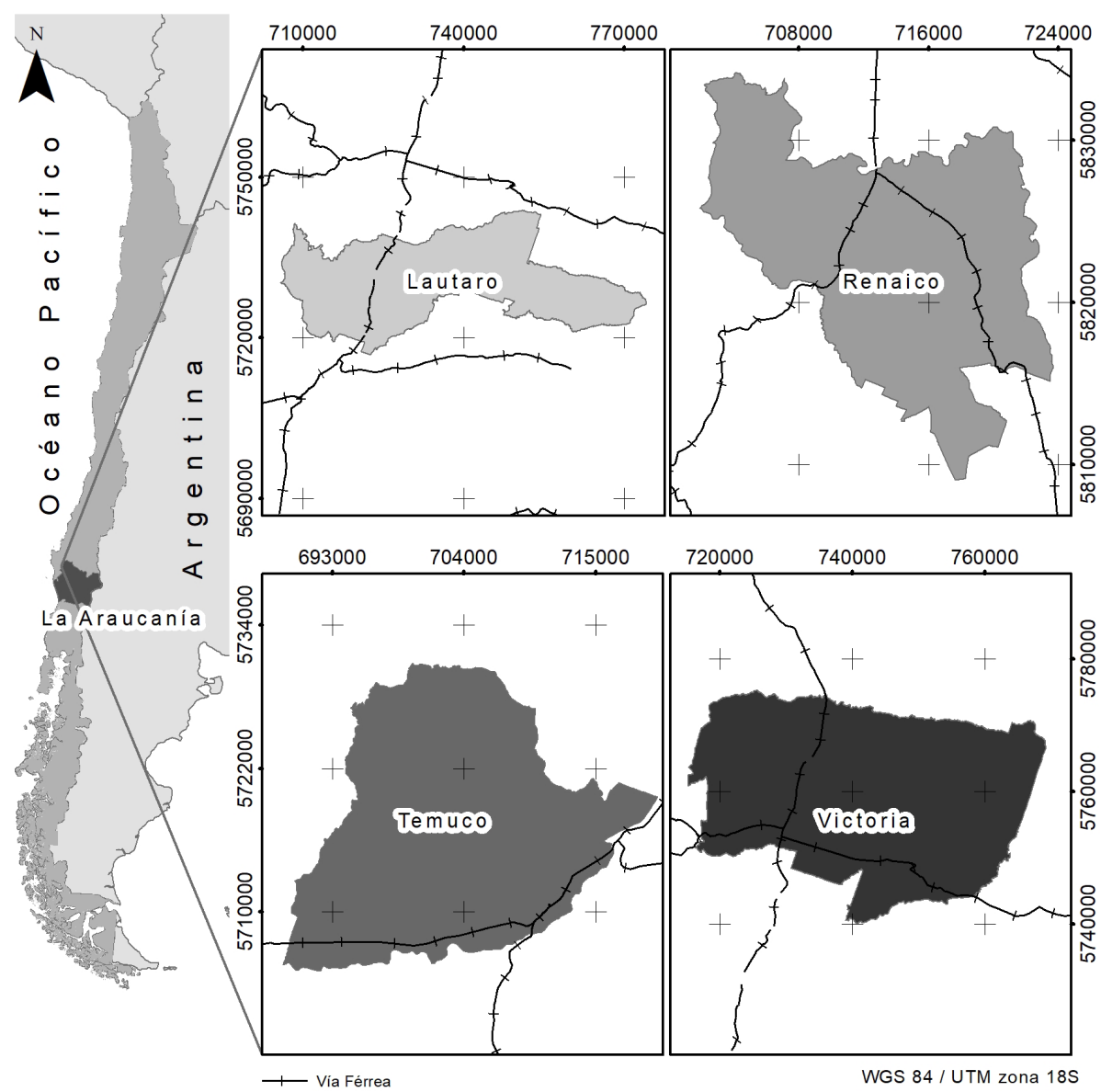

Fig. 1. Mapa de ciudades de estudio Fuente: elaboración propia.

la vida cotidiana de los habitantes de territorios donde el ferrocarril se insertó y consolidó, aportando relevantes datos respecto a la percepción de este ferrocarril en la vida diaria.

Para Ferrari (2011), existe una clarificadora distinción entre el paisaje ferroviario, comprendido desde los elementos que involucran el ferrocarril (vía férrea, vagones y estaciones), y el paisaje cultural, donde el papel íntegro del ferrocarril se combina con costumbres, pueblos y vínculos afectivos. El paisaje cultural sintetiza e interrelaciona la herencia del territorio con aspectos patrimoniales. En este sentido, cobra vigencia el planteamiento de Delgado (en Godoy y Poblete, 2006), quien concibe el patrimonio desde el sentido de continuidad de las personas, revitalizando la relación entre pasado y futuro, y sus respectivas asignaciones valorativas de utilidad.

Por un lado, el paisaje cultural engloba elementos ferroviarios y territoriales; por otro lado, el patrimonio como actividad en perspectiva y continuidad, provoca que emerjan elementos constitutivos del quehacer respecto al ferrocarril como un elemento que trasciende su condición de objeto inanimado destinado a la movilidad y el transporte. Estudios efectuados 
durante el último tiempo confirman que el ferrocarril en Chile ocupó un rol preponderante en la generación del paisaje cultural y la construcción de asentamientos humanos (Thomson \& Angerstein, 1997; Vergara, 2003; Guajardo, 2007; Guerrero, 2017), transformándose en un hacedor de prácticas cotidianas que permean la vida social de los territorios.

Debido a lo expuesto, cabe enfatizar en la distinción entre patrimonio ferroviario material e inmaterial. En tanto el primero responde a los aspectos arquitectónicos que emergen en relación con la cultura industrial, el segundo da cuenta de los aspectos de carácter antropológico, donde la identidad y el territorio realzan la experiencia (Ortega, 2013). Las estaciones, como lugares ${ }^{4}$ de encuentro y espera, confieren un espacio preponderante en la trama patrimonial de la historia ferroviaria, constituyendo, junto con las locomotoras, un objeto sustancial del patrimonio ferroviario.

Aspectos socioeconómicos confieren al ferrocarril la capacidad de transgredir lo netamente ligado al transporte, en tal sentido, para Méndez y Cuellar (2017), el patrimonio ferroviario deviene en el conjunto de bienes culturales que encajan en diversas tipologías socioeconómicas y culturales, propiciando que "los bienes heredados de las explotaciones ferroviarias los incluimos en el subgrupo de patrimonio industrial por la relación entre los transportes y la revolución industrial” (p. 277). Aunque esta definición técnica lo liga a aspectos de carácter jurídico, aporta una perspectiva relevante respecto a los estudios del patrimonio industrial y sus derivaciones.

El patrimonio ferroviario, considerando los planteamientos de Ortega (2013), Delgado (en Godoy \& Poblete, 2006) y Méndez y Cuellar (2017), se comprende por su raíz material y experiencial vinculada al territorio y las dinámicas socioculturales que se gestan cotidianamente en función al rol pasado y futuro del ferrocarril, trascendiendo lo ligado al desplazamiento y ocupando un lugar fundamental en el desarrollo histórico de las ciudades. En consecuencia, la puesta en valor del patrimonio ferroviario está directamente asociada con aspectos culturales, como indica Hidalgo (2010), la recuperación y rehabilitación de bienes culturales que puedan ser utilizados, requiere de una conservación integrada e integral.

En una línea similar, Ferrari (2012), identifica el sistema ferroviario como elemento del paisaje patrimonial a diferentes escalas, a saber: urbana, territorial y arquitectónica. En virtud de lo expuesto por la investigadora, cada escala se interconecta con las funciones y objetivos de los circuitos ferroviarios, dejando con su tránsito relevantes aportes respecto a la conforrmación de asentamientos humanos que tributan a la vida urbana a tenor del transporte ferroviario, lo cual entrega diversas conformaciones territoriales.

Para Guerrero (2017), el concepto patrimonio ferroviario está enlazado profundamente con el patrimonio industrial. Los motivos están dados por los vestigios ferroviarios que representan su materialidad, no obstante, para la autora esta perspectiva no da cuenta de los significados ya que "lo relevante del patrimonio material no es los vestigios recuperados y su puesta en valor, sino la historia y memoria recuperada con ello" (Guerrero, 2017, p. 61).

Emerge el concepto de "no lugar" elaborado por Augé (2000), como sitio de transitoriedad y espera. 
Se comprende que el patrimonio, más allá de la relevancia de las convenciones mundiales, abarca la íntima relación entre el objeto y la experiencia de los habitantes de los lugares que conservan, transmiten intergeneracionalmente, se apropian y revitalizan aspectos subjetivos de los objetos, generando un silogismo entre los factores de usos y cambios históricos envueltos en los territorios que contienen elementos patrimoniales. En consecuencia, el patrimonio debe ser comprendido como una categoría cultural que unifica y divide los grupos sociales producto de las relaciones de poder que se gestan entre lo que debe ser preservado y lo que no debe preservarse (García-Canclini, 1999).

Por lo anterior, la vacancia en el ámbito nacional respecto a la revitalización del patrimonio ferroviario confiere a los aspectos culturales un papel preponderante en lo que respecta a la detección de condiciones de riesgo y falta de valoración del patrimonio industrial con énfasis en aspectos ferroviarios (Torres, 2013). Por consiguiente, se torna menester recuperar la subjetividad desde la percepción de las personas involucradas en la historia ferroviaria del país, colaborando en la revitalización testimonial de la memoria narrativa y generando un acercamiento con las propiedades del narrador y su experiencia (Jelin, 2009), más aún cuando se considera el papel de la modernidad y su relación con el pasado y futuro en la construcción de memorias (Iñigo, 2018).

\section{METODOLOGÍA}

Con el objetivo de conocer y explorar las experiencias de los trabajadores ferroviarios de la región en relación con el papel desempeñado por el ferrocarril en la vida cotidiana, la investigación se nutre de la metodología cualitativa para organizar la fase de trabajo de campo y su posterior análisis. El diseño fue de carácter transversal y exploratorio, ya que revitaliza diversas perspectivas y aspectos sociales de la temática planteada (Olabuénaga, 2012).

La metodología cualitativa, al profundizar aspectos subjetivos, permite indagar en diversas categorías que, en este caso particular, refieren a patrimonio ferroviario, paisaje cultural y familia ferroviaria. La primera categoría enfatiza en la relación existente entre la infraestructura y la vida cotidiana de los trabajadores ferroviarios; la segunda categoría da cuenta de la relación entre lo urbano, territorial y arquitectónico, poniendo en tensión la conformación territorial de la región; y la tercera categoría analiza las relaciones interpersonales de los trabajadores ferroviarios en sus rutinas, generando vínculos sociales que influyen en la percepción que tienen sobre su quehacer laboral. Estas tres categorías surgen de la literatura sobre la temática, no obstante, se refuerzan y reconstruyen con sus particularidades a partir de los hallazgos de la presente investigación.

En términos específicos, se utilizó la técnica de la entrevista en profundidad con el objetivo de ahondar en la percepción de los participantes de la investigación, considerando 
una temporalidad amplia que permite construir datos y análisis de manera pausada, creativa e interpretativa (Robles, 2011). La entrevista se diseñó pensando en el perfil específico de los participantes, donde predominan aspectos como masculinidad, transiciones generacionales (jubilados y laboralmente activos) y sentimiento de arraigo por lo ferroviario en la región. Asimismo, el guion de entrevista fue construido en base a los siguientes tópicos: vida cotidiana en el trabajo, conocimiento de la infraestructura ferroviaria, costumbres y tradiciones ferroviarias, relaciones interpersonales entre los trabajadores y expectativas sobre el funcionamiento de ferrocarriles en la región. Antes de desarrollar las entrevistas, se advirtió sobre la confidencialidad de la información entregada y se clarificó el propósito y objetivo de la investigación.

Se entrevistó durante el periodo 2017-2019 a veintitrés trabajadores y extrabajadores ${ }^{5}$ de la empresa Ferrocarriles del Sur (FESUR ${ }^{6}$ ). Las entrevistas fueron realizadas durante la jornada laboral, aprovechando la soledad de muchos de los trabajadores, y también pos jornada laboral, sobre todo en aquellos trabajadores que se encargan de la atención a público. Las sesiones de entrevista promediaron de tres a cuatro encuentros con cada uno de los participantes, resaltando diversos espacios de vida que, junto con involucrar el trabajo, incluyen tiempos de ocio, espacio doméstico, la familia sanguínea y la familia ferroviaria.

Los trabajadores, para convertirse en participantes del estudio, debieron cumplir criterios de selección, los cuales fueron intencionados con el propósito de resguardar los objetivos de la investigación. Los criterios fueron: residir en la región, trabajar o haber trabajado en ferrocarriles y que algún familiar directo haya trabajado en la Empresa de Ferrocarriles del Estado ( $\mathrm{EFE}^{7}$ ). Aquellos que vivieran en una región ajena a La Araucanía, no hubiesen trabajado en La Araucanía y llevaran menos de cinco años ligados a la empresa de ferrocarriles, no fueron considerados como posibles participantes.

Las ciudades donde se desarrolló el trabajo de campo fueron Temuco, Lautaro, Renaico (Fig. 4), Victoria (Fig. 3) y la localidad de P.U.A (Fig. 2) ${ }^{8}$. Todas ellas pertenecen a La Araucanía y tal como refleja la literatura asociada a la temática ferroviaria, convergen en el desarrollo y crecimiento/estancamiento económico y sociodemográfico inicial que experimentaron durante la segunda mitad del siglo XIX, en directa relación con la construcción y funcionalidad del transporte ferroviario.

Los nombres reales de los entrevistados fueron cambiados con el objetivo de resguardar su anonimato.

6 Sociedad Anónima fundada en 1995. Se encarga del Servicio Regional Victoria-Temuco. Funciona como filial de la empresa de Ferrocarriles del Estado.

7 Empresa creada a fines del siglo XIX a partir de la integración de empresas del Estado de Chile. Dentro de las empresas filiales que existen en la actualidad, Ferrocarriles del Sur S.A. se hace cargo del servicio de pasajeros Regional Victoria-Temuco.

8 Cabe señalar que existen diversas historias que dan origen al nombre de esta localidad. La primera, rastreada en el libro Diez años en Araucanía 1889-1899 escrito por Verniory, permite un acercamiento a su denominación a partir de dos personajes que emergen de la construcción de una parte de la vía férrea de la región, se trata del general Gregorio Urrutia y Tomás Albarracín. De ambos proviene Paradero Urrutia Albarracín (P.U.A.). La otra versión encuentra asidero en la denominación de una planta mapuche y el estero llamado Púa. 


\section{RESULTADOS}

El ferrocarril de La Araucanía: más allá del transporte público

Uno de los ejes que mayor tensión provoca entre los participantes surge en la percepción reduccionista del ferrocarril como objeto con dedicación exclusiva al transporte. Para los entrevistados, en las últimas décadas este dispositivo traspasa su objetivo inicial relacionado al transporte y la vigilancia que conllevó su inserción en la región ${ }^{9}$. El ferrocarril constituye un componente esencial en sus historias de vida, siendo eje articulador de su vida cotidiana en diversos espacios de interacción. La trascendencia del espacio laboral a otros ámbitos de la vida cotidiana recae en la versatilidad del ferrocarril como un objeto que congrega y genera articulación afectiva entre los trabajadores, usuarios del servicio y habitantes de la región. Este vínculo queda registrado en perspectiva pasada y presente. Al respecto, Miguel, 45 años, trabajador de la estación de Lautaro sostiene:

Acá no soy solo yo el que se hace cargo porque esto no es algo nuevo, viene de muchos años. Antes de mí había otros viejos que hacían esta pega. Mi abuelo también fue ferroviario, y yo cuando chico lo veía trabajar y me entusiasmaba la idea de estar cerca de los trenes, siempre me gusto esto ... cuando se cacha que el tren no tiene que ver solo con hacerlo funcionar es, como le dijera, un estilo de vida. ¿Me entiende?

La comprensión del ferrocarril como medio de transporte anhelado coexistía perceptivamente en la mayoría de los entrevistados desde la niñez. La referencia al ferrocarril como un objeto que cumple funciones de cohesión social permite comprender que las transformaciones económicas y culturales provocan una clara distinción entre el pasado y el presente. Mientras el pasado resultaba beneficioso, con bonanza económica y de mayor unión grupal; el presente refleja decadencia a nivel de estabilidad económica, disminución de personal y de reducción de las rutas ferroviarias. En este sentido, Diego, 56 años, trabajador de la estación de Victoria, comenta:

El guardia de vigilancia, los maquinistas, el banderista, el mensajero...en total aquí había como 70 personas trabajando. Ahora no queda nadie... un par por aquí, un par por allá...y ya nadie quiere trabajar ahí. Ya no conozco a casi nadie, a veces voy a darme una vuelta, pero no es lo mismo. Había tres ramas importantes en ferrocarriles que eran el transporte, vía y obra y maquinista. Todos podíamos llegar a trabajar en cualquiera de ellas, se hacía carrera, empezábamos de abajo, si había ganas y trabajo durabas toda la vida en el tren. Trabajar aquí era como ir a un instituto.

9 En La Araucanía, los ramales durante los siglos XIX y XX alcanzaron diversos lugares, cabe destacar algunos ramales como Renaico-Traiguén, Temuco-Carahue, Púa-Lonquimay, Quino-Galvarino y Saboya-Capitán Pastene. 
El relato de Diego refleja una nostalgia con tintes de frustración producto del estado actual del ferrocarril que, en perspectiva pasada, permitía un buen pasar entre los trabajadores, asegurando una vida entera destinada al transporte ferroviario sin mayores vaivenes económicos y en un entorno social que enaltecía y reconocía tanto el papel del ferrocarril como el de sus trabajadores en el desarrollo de las ciudades. Lucía, ayudante de maquinista, 34 años, sostiene: "el ferrocarril aún tiene un rol social, antes era mucho más, pero una se da cuenta cuando escucha a las personas, sobre todo las del campo que sin el tren no pueden moverse a otros lados".

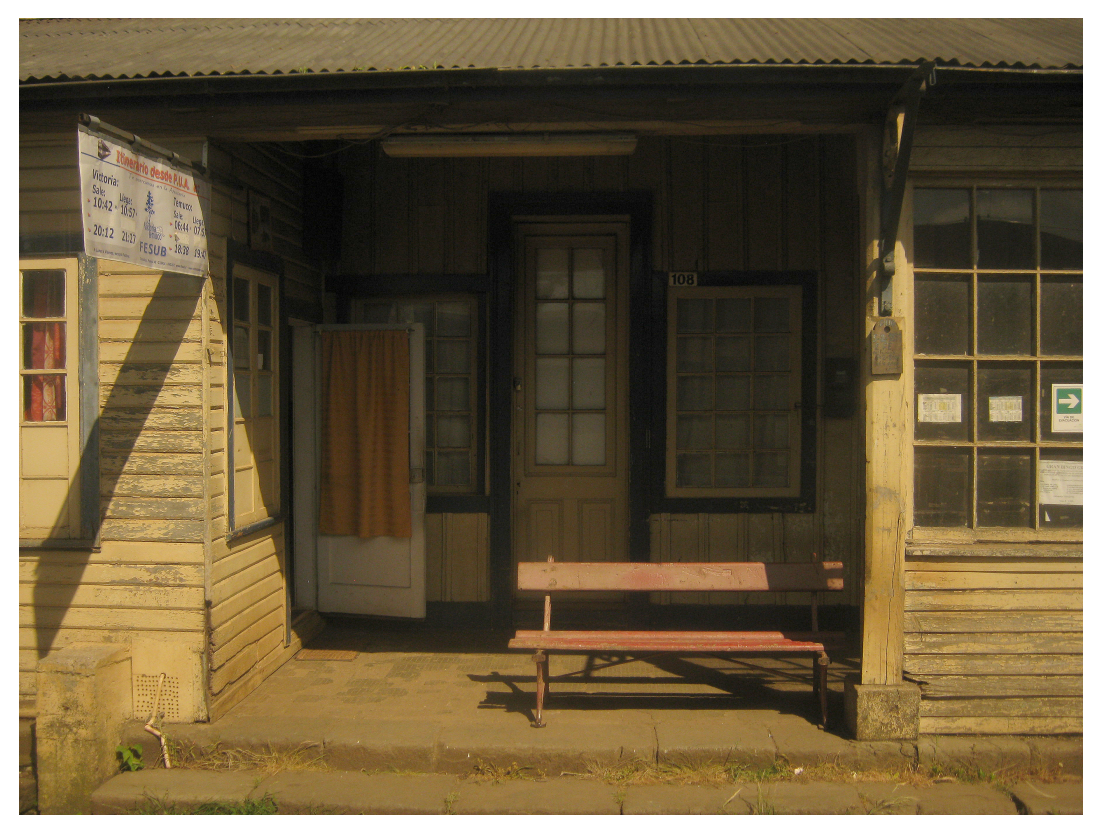

Fig. 2. Estación P.U.A. Entrada a la estación.

Si con anterioridad el ferrocarril tenía un papel preponderante en el tejido social de la región, en la actualidad se identifica que, producto de las condiciones mínimas de operatividad y conectividad, se reciente su potencialidad, no obstante, en términos cualitativos sigue cumpliendo un papel protagónico (Riquelme, 2017b), sobre todo para aquellos habitantes de la ruralidad que viven alejados de los centros urbanos.

Acá en Renaico el tren era como todo un espectáculo, si hasta había gente que estaba horas enteras en la estación para solo mirar quién subía y quién bajaba. El tren nos dio mucha vida y también identidad, por ejemplo, las tortilleras, el turismo en el río, tantas cosas... Fíjese que hasta el día de hoy nos acordamos del tren y salen anécdotas y pelusiamos a los viejos que trabajaron por ese tiempo y aún quedan vivos ... si usted va ahora a la estación va a ver lo penca que está y lo muerta que se ve, es triste eso (Roberto, extrabajador de ferrocarriles, 67 años). 
Yo pienso que el tren debería tener mucho más valor por parte del gobierno, y no tiene nada que ver con los colores políticos. ¿Vio las máquinas españolas que tenemos? No tienen nada que ver con las de antes, con todo respeto, pero son como baquelita éstas. Igual la gente le agradece a uno el servicio, es distinto viajar en tren, es como un regalo. La tranquilidad, el paisaje, la comodidad hacen que el tren sea súper valorado por la gente, pero no por los gobiernos (Pedro, movilizador, 39 años).

Los fines constitutivos del ferrocarril como objeto destinado exclusivamente al transporte de pasajeros quedan soterrados producto de la inmensidad de factores socioculturales que emergen e inciden en su reconocimiento tanto en la vida cotidiana como en el paisaje cultural de la región. Los trabajadores ferroviarios cumplen un papel fundamental en la revitalización del ferrocarril, sobre todo en esferas sociales que trascienden el desplazamiento, tornándose un mecanismo de interacción que incide de manera global en la vida social de las ciudades.

\section{La familia ferroviaria como matriz constitutiva del funcionamiento de ferrocarriles}

Los espacios de vida de los trabajadores ferroviarios se encuentran íntimamente ligados a las representaciones sociales de sí mismos y la exaltación de la infraestructura ferroviaria, ocupando esta última un rol fundamental en su memoria (Jelin, 2009). El apego por todos los elementos relacionados con lo ferroviario constituye una regla general de los trabajadores. Enaltecer la figura del ferrocarril en los procesos de interacción social constituye un eslabón central en los relatos pesquisados. La historia de vida está ampliamente influenciada por familiares pasados y presentes que entregaron y entregan a EFE y FESUR parte importante de su existencia. De acuerdo con esto, Alonso, 52 años, movilizador, sostiene:

Mi papá trabajaba en ferrocarriles, también mi hermano, ellos trabajaban en maestranza y tracción, eso es locomotora y electricidad. Y se lo pasaban viajando en las rutas y los recorridos que había como Santiago, Osorno, Valdivia, Talcahuano, Temuco, Victoria. Yo trabajé en Curacautín igual como movilizador. También trabajé en Temuco cinco años. Llegué a ser inspector de tráfico en Victoria.

La herencia del trabajo ferroviario, como acto adquirido culturalmente, está íntimamente entrelazada con el conocimiento del territorio nacional (Guerrero, 2012). Trabajar en movimiento constituye una parte fundamental del quehacer del movilizador, aspecto que conlleva a extrapolar y volcar sentimientos personales al espacio laboral, tal como señala Héctor, 57 años: "uno termina viendo las máquinas como las segundas señoras. Se les toma harto cariño y costumbre".

Respecto a las transformaciones en los vínculos afectivos entre los trabajadores, se detecta una transformación en la manera de interactuar y cohesionar el grupo de trabajadores. 
En virtud de ello, Ariel, 69 años, ferroviario jubilado, sostiene:

Antes, por ejemplo, cuando se hacían juntas, se reunían setenta viejos aquí, hacían asados, hacían juegos. Es que antes aquí había mucha gente trabajando, entonces ahí salían sus tallas, sobrenombres, entonces eso era compartir. Había un sentido de hermandad en ferrocarriles, si ibas a algún lado y decías que eras trabajador del ferrocarril, sabías que tenías familia en esa ciudad, familia en el trabajo, no sé si me entiendes... y después era lo mismo con personas que venían a Victoria.

Una de las posibles respuestas a la fragmentación en las formas de interactuar, unir y reconocer a los trabajadores, se origina en los cambios que atravesó EFE. Los entrevistados manifiestan que la privatización del servicio influyó profundamente en la fragmentación del grupo. En este aspecto, uno de los participantes sostiene:

Antes todos éramos EFE y ahora está Tren Central, FESUR y otros más, que son todos articulares. Y ahora uno no se siente taaan...o sea, uno sigue siendo ferroviario. Hay algunos viejos que trabajan aquí que aún son EFE, yo soy FESUR, $y$ todos hacemos las mismas funciones, los mismos trabajos, pero ya es distinto, porque por ejemplo una comida ahora es solo para los de FESUR o solo para los EFE, entonces eso ya te empieza a dividir, ya no se siente tan familia (Pedro, movilizador, 39 años).

El "hacer carrera de ferroviario", junto con entregar cierta estabilidad emocional y económica, involucra reconocimiento y fidelización por parte del trabajador hacia EFE, pero con la llegada de capitales privados al control de la empresa, los cambios constantes de personal y reestructuración del servicio, se terminó por corroer una parte importante del tejido social de los trabajadores ferroviarios.

El sentimiento de abandono e incertidumbre que sienten los trabajadores ferroviarios se respalda en realidades que son descritas por los participantes respecto a la reducción de personal, deterioro de la infraestructura ferroviaria con el paso del tiempo y una baja en la organización política y social de los trabajadores. Todos estos aspectos están asociados a la postergación de la familia ferroviaria en los espacios de poder al interior de la empresa ferroviaria, que alguna vez les permitió mejorar su calidad de vida. Como síntoma de ello, emerge la incertidumbre entre los trabajadores respecto al devenir de ferrocarriles en la región y el país; Jorge, 35 años, movilizador, sostiene:

Cada vez se le da menos interés al tren, aunque digan que abrirán estaciones o las reabrirán con trenes remodelados o harán tours o como los llamen ahora, no 


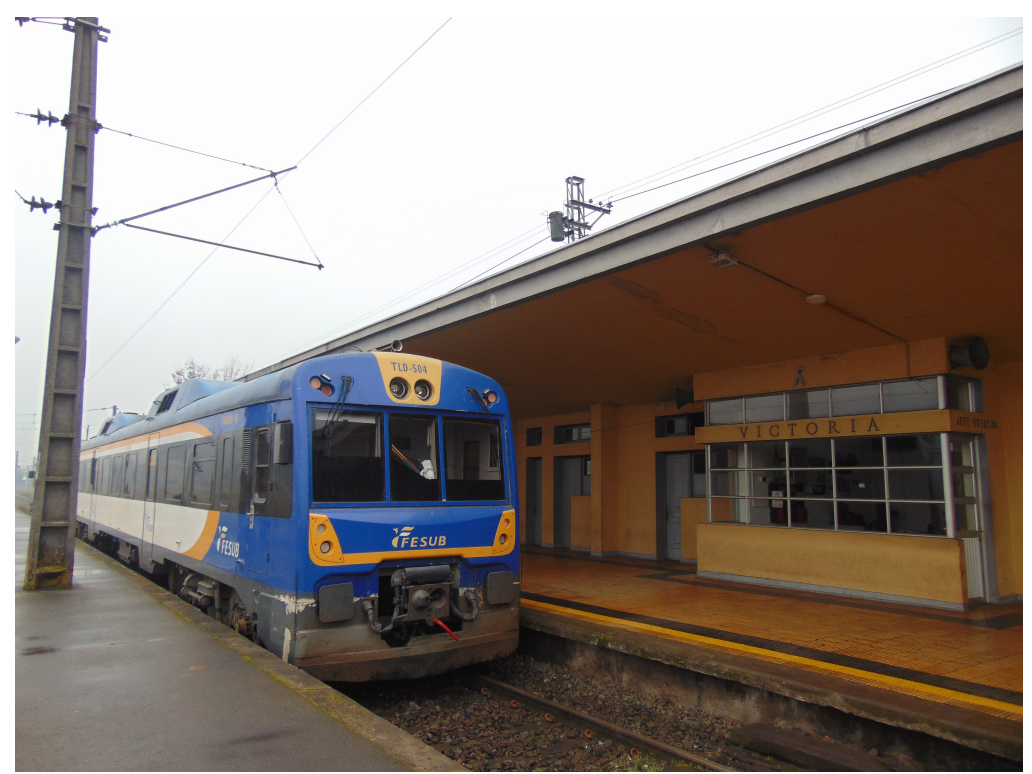

Fig. 3. Estación de Victoria Ferrocarril de pasajeros a la espera de emprender un nuevo viaje con dirección a Temuco.

es ni será nunca lo mismo. Me parece que están inventando las cosas, quieren lo viejo, pero modernizado, eso no me gusta, porque quieren revivir cosas que ya se murieron. La cortesía o el amor con que se trabajaba antes no volverá nunca más, el cariño con que uno trabajaba o el sacrificio de uno por ferrocarriles ya no está, y si está no lo valoran, tampoco lo harán. Aunque digan que se abrirán más líneas o se quieren despertar los ramales de pueblitos.

La familia ferroviaria, como institución crucial en la historia de los trenes de Chile, para algunos entrevistados, en la actualidad carece de fuerza política y sentido grupal afectivo. El desempeño y la organización grupal han sido reemplazados en pos de la inserción del sentimiento de precariedad, con la respectiva incertidumbre y fragmentación que se instalan en las lógicas de automatización. Los trabajadores ferroviarios, aunque reconocen la importancia de la unión y el reconocimiento entre pares, ya no cuentan con un respaldo institucional sólido que entregue espacios para la socialización más allá de los espacios de trabajo. De acuerdo con lo expresado, Gonzalo, 64 años, afirma: “yo sé que en los ochenta empezó a quedar más la embarrá. ¡El neoliberalismo!, esta cuestión de que cada uno rema $p a^{\prime}$ su $l a o^{\prime}$. Ya no hay el compañerismo de antes".

El papel del ferrocarril en el paisaje cultural de la región: más allá de los vagones y rieles

En gran cantidad de las treinta y dos comunas que conforman la región, existen vestigios de lo que tiempo atrás se alzó como imponentes estructuras ferroviarias. Esa historia no muy 
lejana continúa presente en la memoria de los habitantes, como parte constitutiva de su ser social (Obreque, 2001). Los trabajadores ferroviarios, actores fundamentales en el desarrollo del patrimonio ferroviario, reconocen la importancia del ferrocarril en la gestación del paisaje cultural. Antonio, 44 años, trabajador de la estación de Victoria, relata:

Al salir de la estación [Victoria] usted se puede dar cuenta que hay varios lugares que se conforman por el tren. La plaza, la venta de comida, los puestos de más allá y los oficios de la gente nacen con la existencia del tren. No por el azar, sino que por el tren.

La percepción de Antonio conlleva nuevamente a considerar la trascendencia del ferrocarril más allá del patrimonio material, reconociendo implícitamente la importancia de las estaciones en la organización de las ciudades. Esta opinión tiende a generalizarse entre los participantes de la investigación, ya que identifican las estaciones como lugares clave en la generación de actividades y participación ciudadana.

Yo eтресе́ en Tетисо hace muchos años, cuando el sector Feria Pinto no era ni la mitad de lo que es hoy en día [...] Cerca del tren tenía que haber de todo, comercio, hospedaje, entretención, comida, lo que el viajante quisiera. Y esas cosas quedan, no se van de la noche a la mañana. Usted mira ahora la Feria y se va a dar cuenta que es como un centro chico en Temuco, pero antes era un lugar más importante todavía. Yo hago memoria y me recuerdo de montones de gente moviéndose de allá pa' cá.

Para los entrevistados, el viaje en tren no termina al descender del vagón. Lo que acontece en las estaciones y el espacio circundante a la estación es tan relevante de la historia ferroviaria como el propio viaje. En este sentido, los trabajadores ferroviarios identifican lugares y personas altamente representativos del paisaje cultural ferroviario de la región. Arnaldo, 62 años, extrabajador ferroviario, comenta:

Acá en Renaico fue muy lindo el tren... ¿Usted sabe de las tortilleras? Eran, como decirle, trabajadores más del tren. Andaban por todos lados vendiendo las tortillas y la gente que viajaba en tren las buscaba pa' comprarles. Eran muy apetecidas. Esos recuerdos van quedando... acá usted habla de las tortilleras y los más viejos altiro le van a contar una anécdota, una historia relacionada con ellas.

De manera similar, se reconocen oficios que emergen en concordancia con la vida social que se provoca desde los ferrocarriles. Antonio, 44 años, señala: "acá quedaron algunos viejitos que antes vendían cosas en la estación, no sé qué hacen ahora, pero te 
cuentan que vendieron trabajos de cuero, eran como artesanos, ofrecían sus cinturones y pulseras. Ellos saben toda la historia del tren [...] de la ciudad también, conocen a todos". No es casual la emergencia de espacios públicos vinculados al comercio en las inmediaciones de las estaciones. En estos lugares se puede observar que aún continúan funcionando puestos de comida, ropa y artesanía, reproduciendo lógicas de interacción en estrecha relación con el servicio Victoria-Temuco aún vigente, no obstante, los entrevistados distinguen diferencias entre unas estaciones y otras.

Mire, yo le voy a decir que no es lo mismo la estación de Lautaro que la de Temuco. Acá usted ve que esto está medio muerto. Está como desolada esta estación... y antes era muy bonito todo. En Temuco sigue habiendo vida en la estación. Usted sale de la estación y se encuentra con la feria, lo mismo pasa en Victoria. Pero no siempre fue así, Lautaro años atrás movió harta gente, esta estación era bien encachá. (Rosendo, extrabajador en Estación Lautaro).

El paisaje cultural, dinámico y propenso a vicisitudes que escapan de los deseos individuales, cobra sentido cuando los habitantes del territorio utilizan y transforman las dinámicas cotidianas, integrando diversas actividades, lugares y personas en los espacios de socialización. Tal como se plantea en la Fig. 5, el patrimonio ferroviario cumple un rol clave en la organización del espacio urbano, fusionando la impronta de las estaciones con las diversas actividades que se desarrollan desde el funcionamiento del ferrocarril, las cuales aportan identidad y tradición a la región.

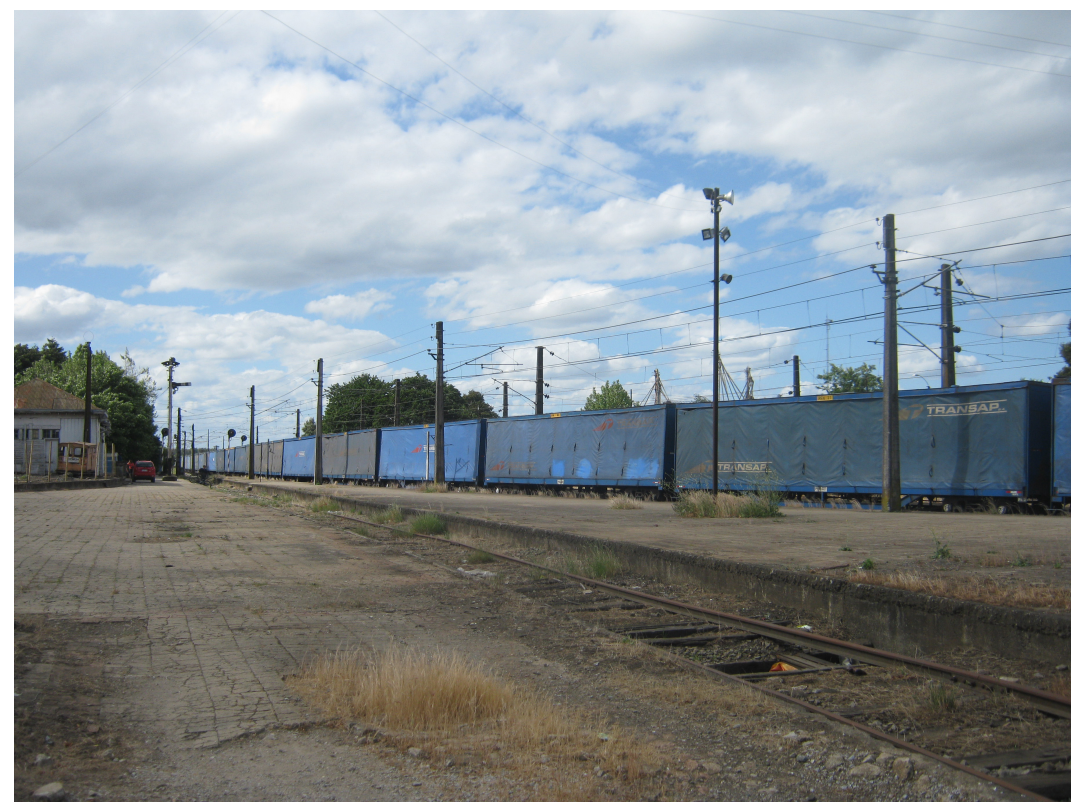

Fig. 4. Estación de Renaico. Avance de un tren de carga observado desde la estación. 


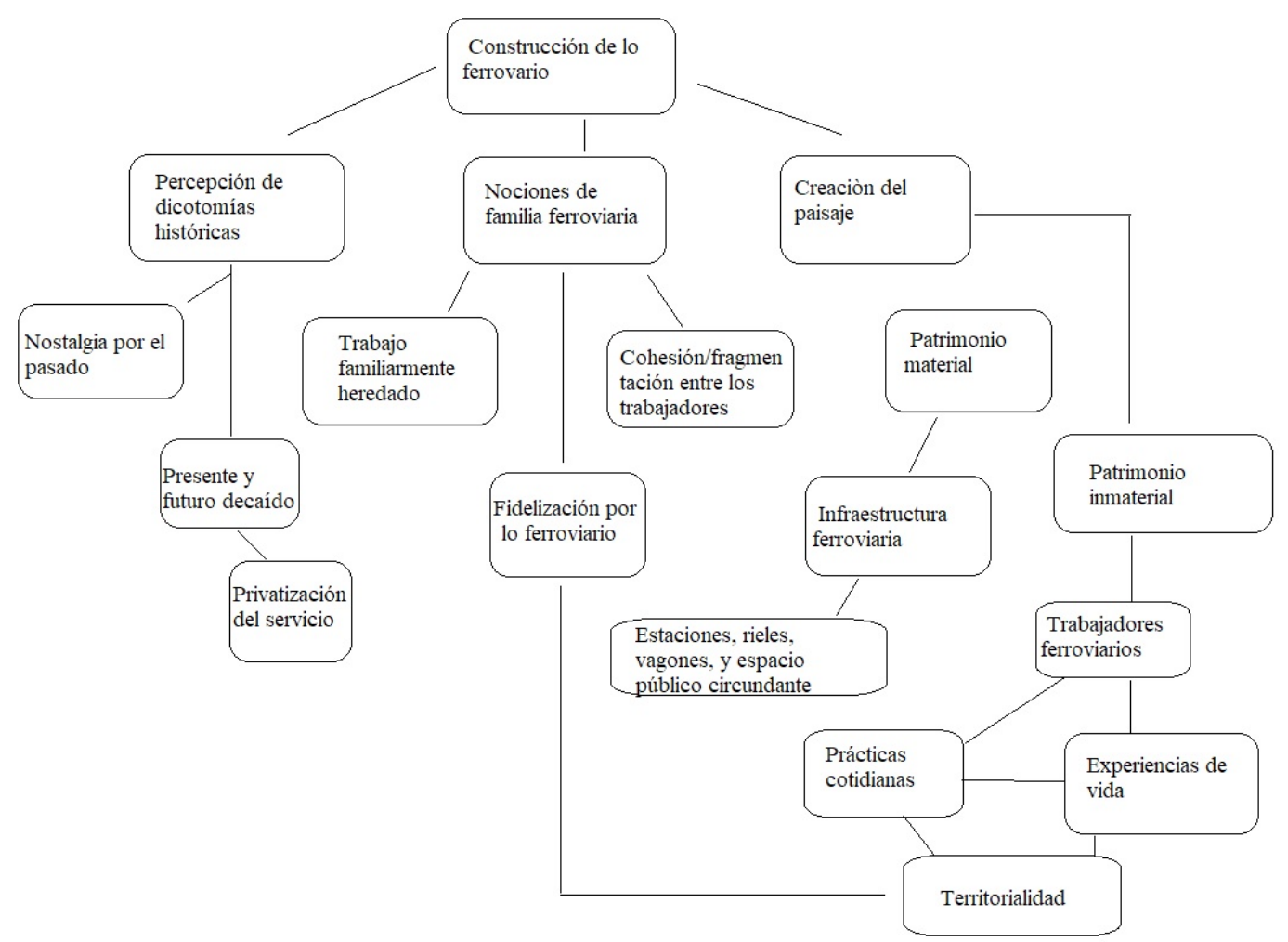

Fig. 5. Síntesis conceptual. Elaboración propia.

\section{CONCLUSIONES}

El patrimonio ferroviario constituye un área de interés incipiente en las investigaciones chilenas, encontrando trabajos que tratan el patrimonio industrial y su derivación en lo ferroviario (Guerrero, 2012; Ortega, 2013). Con el objetivo de avanzar en el reconocimiento intrínseco entre los aspectos materiales e inmateriales de la impronta ferroviaria en la historia nacional, urge incorporar la percepción de los trabajadores ferroviarios, como actores clave en el funcionamiento y desarrollo de los territorios cubiertos por los ramales o servicios regionales, revitalizando así la memoria como sostén del patrimonio ferroviario. En este sentido, el presente trabajo permitió recopilar testimonios que evocan la memoria como eje matriz de la historia ferroviaria del país, memoria que se niega a abandonar un objeto urbano que ocupó y ocupa un lugar fundamental en sus espacios de vida.

La consolidación del modelo neoliberal se torna un hito preponderante en la historia ferroviaria reciente (Guerrero, 2017), lo cual afectó negativamente la cohesión grupal e introdujo sentimientos de desamparo e incertidumbre frente al devenir del trabajo individual y el funcionamiento de los ferrocarriles en Chile. La mixtura entre el pasado y el presente se funde en la trascendencia del legado (Delgado en Godoy y Poblete, 2006) que se encuentra desde el papel del ferrocarril, generando un sentimiento contradictorio de negación y 
resignación frente al complejo escenario actual, donde existe una evidente decadencia y abandono del servicio ferroviario.

Para los entrevistados, la importancia del ferrocarril es múltiple, trasciende lo económico y se instala en diversas esferas de la vida cotidiana. La herencia familiar por el trabajo ferroviario cobra sentido, escapándose del núcleo consanguíneo para formar nuevas familias desde un trabajo que unifica bajo un sentimiento de apego hacia lo ferroviario. Tanto la familia nuclear como la familia laboral comparten el sentido de pertenencia por los viajes y fierros. Pese a ello, en los tiempos actuales la familia laboral cada vez resulta menos relevante en la vida de los ferroviarios, lo que fue acrecentándose a medida que la privatización del servicio se tornó más evidente.

La cultura ferroviaria implica una memoria materializada en sentidos del pasado, que son plasmados en vehículos de la memoria (Jelin, 2009) como estaciones, espacio público circundante a las estaciones, vagones y rieles, lo que comúnmente es denominado patrimonio ferroviario material. Para los entrevistados, el ferrocarril simboliza un estado de satisfacción que logra encarnarse en experiencias de júbilo, inmortalizándose y transformándose en recuerdos atiborrados de esplendor. Para ellos, en y desde el ferrocarril acontecieron los mejores momentos de sus vidas. En este sentido, la memoria permite reconstruir y revitalizar el patrimonio ferroviario de La Araucanía, más aún, en tiempos donde la inmediatez y la aceleración no dan tregua a los recuerdos, la contemplación y la reconstrucción de un pasado como estado inherente del presente y el futuro.

Quedan pendientes de analizar algunas dimensiones que escapan de los objetivos del presente trabajo pero que sí resultan de interés para las ciencias sociales. En primer lugar, se evidencia la masculinización del trabajo ferroviario, lo cual se vio acrecentado en percepciones machistas sobre el mismo trabajo de un ferroviario y la división de las funciones según el sexo, reduciendo los espacios laborales de las mujeres, los cuales son observados como secundarios e intrascendentes en el relato de los trabajadores. En segundo lugar, resalta la escasa capacidad de organización política de los trabajadores, lo que provoca fragmentación y ralentiza su capacidad de organización frente a situaciones de negociación con las autoridades de la empresa. Por último, destaca el fatalismo respecto al futuro del ferrocarril en la región, lo cual conlleva al planteamiento de visiones negativas que resaltan un pasado nostálgico que no podrá ser superado por nuevas experiencias.

Finalmente, permanecen innumerables páginas por escribir respecto al desarrollo del ferrocarril en la región. Este trabajo constituye una mínima pieza respecto a la construcción de la historia reciente del ferrocarril desde la percepción de un grupo de trabajadores que destinó y destina parte importante de sus vidas al funcionamiento del ferrocarril en la región, haciendo de sus historias de vida forma y parte de la identidad de la región y el desarrollo social del sur de Chile. El patrimonio ferroviario debe ser entendido no solo desde los aspectos materiales, la subjetividad constituye un eslabón central en su derrotero epistemológico. 


\section{REFERENCIAS}

Abhishek B., Josephine P., \& Taha C. (2014) Industrial railway heritage trains: the evolution of a heritage tourism genre and its attributes. Journal of Heritage Tourism, 9, 2, 114-133. Alliende, P. (1993). Historia del ferrocarril en Chile. Santiago de Chile: Goethe Institut-Pehuén.

Alliende, P. (2001). La Construcción de los Ferrocarriles en Chile 1850-1913. Rev. Austral Ciencias Sociales, 5, 143-161.

Augé, M. (2000). Los no lugares. Espacios del anonimato. Barcelona: Gedisa.

Burman, P., \& Stratton, M. (1997). Conserving the Railway Heritage. Londres: Taylor \& Francis. Censo. (2017). Resultados Censo. Disponible en: http://resultados.censo2017.cl/

Delgado, A., Campos, A., \& Fiñana, F. (2007). La recuperación del patrimonio ferroviario llevada a cabo por Fundación Río Tinto. Cuenca minera de Riotinto (Huelva). De Re Metallica, $8,19-28$.

Douet, J. (Ed.) (2012). Industrial heritage re-tooled. Lincolnshire: Routledge.

Ferrari, M. (2011). Patrimonio ferroviario y desarrollo sostenible en el noreste argentino. Líneas de intervención. Labor \& Engenho, 5(3), 1-15.

Ferrari, M. (2012). Paisaje y patrimonio en la línea ferroviario ‘Jujuy-La Quianca'. Una propuesta de reutilización para el desarrollo local. Labor \& Engenho. 6(1), 89-108.

García-Canclini, N. (1999). Los usos sociales del Patrimonio Cultural. En E. Aguilar-Criado (Ed.), Patrimonio Etnológico. Nuevas perspectivas de estudio (pp. 16-33). Consejería de Cultura. Junta de Andalucía.

Godoy, M., \& Poblete, F. (2006). Manuel Delgado: Sobre antropología, patrimonio y espacio público. Revista Austral Ciencias Sociales, 10, 49-66.

Guajardo, G. (2007). Tecnología, Estado y Ferrocarriles en Chile, 1850-1950. Ciudad de México: Fundación de los Ferrocarriles Españoles, Universidad Nacional Autónoma de México.

González, J., \& Bernedo, P. (2013). Cartografía de la transformación de un territorio: La Araucanía 1852-1887. Revista de geografía Norte Grande, 54, 179-198.

Guerrero, R. (2012). Patrimonio cultural mundial, territorio y construcción de ciudadanía. Construcción y apropiación social del patrimonio cultural de la ciudad de ValparaísoChile. Scripta Nova, 16, 387-424.

Guerrero, R. (2017). Memorias, significados y olvidos en la construcción social del patrimonio ferroviario del Sur de Chile. Revista Austral de Ciencias Sociales, 33, 59-76.

Hidalgo, C. (2010). El patrimonio minero-industrial y ferroviario: nuevos recursos para nuevos turismos. Universidad Autónoma de Madrid. Tesis inédita. Ms.

Iñigo, I. (2018). Sobre la relación entre memoria y política Contribuciones del pensamiento de Hannah Arendt para el campo de estudios de la memoria. Sophia Austral, 22, 163-181. Jelin, E. (2009). ¿De qué hablamos cuando hablamos de memorias? Los trabajos de la memoria, 1-17. Disponible en; www.cholonautas.edu. pe/modulo/upload/JelinCap2.pdf

Maia, L., Galvão, R., \& Dias, R. (2010). Turismo y patrimonio ferroviario: un estudio sobre el 
Trem da Vale (MG) - Brasil. Estudios y perspectivas en turismo, 19(3), 394-408. Marín, S. (1901). Estudios de los ferrocarriles chilenos. Santiago de Chile: Cervantes. Méndez, R., \& Cuéllar, D. (2017). Apuntes sobre la construcción del patrimonio ferroviario en España durante el siglo XX: Identidad y museos. Oculum Ensaios, 14.

Olabuénaga, J. (2012). Metodología de la investigación cualitativa. Bilbao: Universidad de Deusto.

Obreque, P. (2001). Las tortilleras de Renaico. Temuco: Editorial Pillán.

Ortega, A. (2013). Rieles que unen. Patrimonio ferroviario y configuración del paisaje cultural urbano del ferrocarril al Sur entre Estación Central y San Bernardo (1905-2013). Tesis Magíster. Pontificia Universidad Católica de Chile. Ms.

Riquelme, H. (2017a). Transformaciones sociales en la historia reciente del ferrocarril de La Araucanía (Chile). Patrimonio material e inmaterial durante el periodo 1990-2015. Memorias del XVIII Congreso Colombiano de Historia, 18 (24), 47-62.

Riquelme, H. (2017b). El ferrocarril de La Araucanía: ¿patrimonio móvil?. VIII Jornadas de Investigación en Antropología Social Santiago Wallace, 8, 530-542.

Riquelme, H., \& Lazo, A. (2019). Trazando rutinas: el papel del ferrocarril en las prácticas cotidianas y movilidades interurbanas de habitantes de La Araucanía, Chile. Urbe. Revista Brasileira de Gestão Urbana, 11.

Robles, B. (2011). La entrevista en profundidad: una técnica útil dentro del campo antropofísico. Cuicuilco, 18(52), 39-49.

Thomson, I., \& Angerstein, D. (1997). Historia del Ferrocarril en Chile. Santiago de Chile: Centro de Investigaciones Diego Barros Arana, Dibam.

Torres, C. (2013). Los riesgos por el "abandono cultural" del patrimonio industrial: maestranzas ferroviarias en Chile. Apuntes, 26(2), 52-67.

Vergara, F. (2003). Rieles y durmientes, una vía al progreso. Antecedentes de la organización social y económica de la Empresa de FF.CC. del Estado, Valparaíso, Santiago (18521875), Valparaíso, Chile. Valparaíso: Editorial Puntángeles.

Verniory, G. (2005). Diez años en Araucanía. 1889-1899. Santiago de Chile: Pehuén.

Yuln, M., Montecelli, F., \& Carrizo, S. (2017). Patrimonio ferroviario, un vehículo para la valoración del territorio. Rehabilitación y refuncionalización de talleres en el Noroeste de la Provincia de Buenos Aires. Revista de Turismo y Patrimonio Cultural, 15(4), 883896. 